\title{
Cloning and Characterization of a cDNA Encoding an Elicitor of Phytophthora parasitica var. nicotianae That Shows Cellulose-Binding and Lectin-Like Activities
}

\author{
François Villalba Mateos, Martina Rickauer, and Marie-Thérèse Esquerré-Tugayé \\ Centre de Physiologie Végétale, UMR 5546 UPS-CNRS, Université Paul Sabatier, 118, route de Narbonne, \\ 31062 Toulouse cedex, France \\ Accepted 5 September 1997.
}

\begin{abstract}
Phytophthora parasitica var. nicotianae produces a 34-kDa glycoprotein elicitor (CBEL) that is localized in the cell wall. A cDNA encoding the protein moiety of this elicitor was cloned and characterized. The deduced amino acid sequence consisted of two direct repeats of a cysteine-rich domain, joined by a Thr/Pro-rich region. Although having no general homology with published sequences, the positions of the cysteine residues in the two repeats show a conserved pattern, similar to that of the cellulose-binding domain of fungal glycanases. CBEL did not possess hydrolytic activity on a variety of glycans, but bound to fibrous cellulose and plant cell walls. In addition, it exerted a lectin-like hemagglutinating activity. Infiltration of tobacco leaves (cultivar 46-8) with this molecule elicited necrosis and defense gene expression at $150 \mathrm{nM}$. Elicitor pretreatment of this tobacco cultivar resulted in protection against subsequent inoculation with an otherwise virulent race of $P$. parasitica var. nicotianae. All these biological activities were exerted within a low concentration range. This is the first report that a fungal elicitor exhibits cellulose-binding and lectin-like activities. The possible implications of such a multifunctional elicitor in plant-microbe interactions are discussed.
\end{abstract}

Cell surfaces are believed to play a key role in early interactions between plants and microorganisms. Support for this hypothesis was first provided when Ayers et al. (1976) reported that fungal cell walls contain active fragments that elicit defense responses in plants. Many elicitors have been isolated since then from fungi. Thus, another cell wall-derived elicitor has been obtained from Puccinia graminis, and characterized as a glycoprotein that induces lignin biosynthesis in wheat (Kogel et al. 1988). However, most fungal elicitors purified to date have been isolated from the culture medium of fungi grown in vitro or from intercellular washing fluids of infected plants. They were purified on the basis of their elicitor activity on host and nonhost plants, and found to be glycoproteins and peptides.

Corresponding author: M. T. Esquerré-Tugayé; Telephone: (33) 56155 67 61; Fax: (33) 5615583 78; E-mail: esquerre@cict.fr

Nucleotide and/or amino acid sequence data have been submitted to the EMBL Data Library as accession number X97205.
Many elicitors have been isolated from the culture filtrate of various Phytophthora spp. Thus, a 46-kDa glycoprotein inducing defense in tobacco has been purified from Phytophthora parasitica var. nicotianae cultures (Farmer and Helgeson 1987). In addition, two glycoproteins of molecular mass 42 and 32 $\mathrm{kDa}$, secreted by $P$. sojae and $P$. megasperma, respectively, have been described that induce defense reactions in the nonhost plants parsley and tobacco, respectively (Parker et al. 1991; Baillieul et al. 1995). Another class of elicitors, with molecular mass around $10 \mathrm{kDa}$, are secreted by most members of the genus Phytophthora. These polypeptides, called elicitins, induce necroses and systemic acquired resistance (SAR) on nonhost plants, particularly on tobacco, and are supposed to be involved in nonhost incompatibility (Ricci et al. 1989; Yu 1995). Elicitors that reproduce race-cultivar specificity on their host plant have also been isolated. Accordingly, the peptides AVR4 and AVR9 from Cladosporium fulvum (Schottens-Toma and De Wit 1988; Joosten et al. 1994) and NIP1 from Rhynchosporium secalis (Wevelsiep et al. 1991; Rohe et al. 1995) induce specific necrosis and defense gene expression in host cultivars carrying the corresponding resistance genes.

Although much progress has been made in understanding elicitor-induced defense responses in plants, the intrinsic function of most elicitors and their primary interaction with plants remain unknown. High affinity binding sites have been described for several elicitors (Hahn 1996), but only recently a cDNA coding for such a binding protein has been cloned (Umemoto et al. 1997), allowing more detailed studies in the future.

In the course of our studies on cell surfaces in plantmicrobe interactions, we previously reported the isolation of a glycoprotein of $34 \mathrm{kDa}$, now designed as CBEL, from the mycelium of $P$. parasitica var. nicotianae, and its localization in the cell wall of the hyphae and encysted zoospores of the fungus. It was shown that this glycoprotein induces lipoxygenase activity and accumulation of cell wall hydroxyproline-rich glycoproteins in its host plant, tobacco (Séjalon et al. 1995; Séjalon-Delmas et al. 1997). The present work describes the cloning of a cDNA encoding the protein moiety of the molecule. The elicitor effect of CBEL upon tobacco was investigated, as well as additional activities deduced from its sequence. The possible implications of this novel type of elicitor during the life cycle of the fungus are discussed. 


\section{RESULTS}

\section{Molecular cloning and characterization.}

Cloning of the peptide portion of CBEL was undertaken by a polymerase chain reaction (PCR)-based approach. Toward this end, the glycoprotein was purified to homogeneity and amino acid sequences of peptides derived from the molecule were obtained (Fig. 1A). The amino terminal sequence, established after electrophoresis of the glycoprotein and transfer to a polyvinylidene difluoride (PVDF) membrane, consists of 15 amino acids and begins with alanine, suggesting that CBEL was synthesized as a preprotein. Additional peptide sequences were obtained by hydrolysis of the glycoprotein with trypsin. Upon highperformance liquid chromatography (HPLC) analysis of the digest, the two best-separated peptides, Pep1 and Pep2, were recovered, and their amino acid sequences were determined. The amino terminus was used for the design of the degenerate oligonucleotides $34 \mathrm{~N} 3$ and $34 \mathrm{~N} 4$, and Pep1 for the design of 34.15C ( Fig. 1B). A PCR with these primers and an aliquot of phage suspension containing a cDNA library of race 0 of the fungus did not result in a specific amplification product. However, when primer $34.15 \mathrm{C}$ was used in combination with a primer corresponding to the T3 promoter of the $\lambda$ ZapII vector near the $5^{\prime}$ end of the unidirectionally cloned cDNA, a 700-bp PCR product was obtained. This product was sequenced and found to contain the amino terminal peptide sequence with Cys at the two positions denoted by $\mathrm{X}$, which had not been identified

A

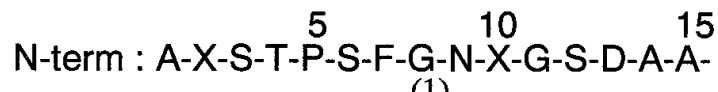
(1)

(2)

Pep 1 :-Q-L-T-D-K-D-Y-Y-G-N-D-I-K-

Pep 2 :-I-G-A-V-S-G-T-L-N-

B

(1) $34 \mathrm{~N} 3: 5^{\prime} \mathrm{AG}(\mathrm{T} / \mathrm{C}) \mathrm{AC}(\mathrm{G} / \mathrm{C}) \mathrm{CC}(\mathrm{T} / \mathrm{C}) \mathrm{AG}(\mathrm{T} / \mathrm{C})$ TTCGGIA A(C/T) 3'

34N4 : 5' TCIAC(G/C)CC(T/C)TCITTCGGI $\mathrm{AA}(\mathrm{C} / \mathrm{T}) \mathrm{3}^{\prime}$

(2) 34N5: 5' GCCTGCTCGACTCCCTCATT 3'

\section{(3) $34.15 \mathrm{C}: 5^{\prime} \mathrm{TC}(\mathrm{G} / \mathrm{A}) \mathrm{TTICC}(\mathrm{G} / \mathrm{A}) \mathrm{TA}(\mathrm{G} / \mathrm{A}) \mathrm{TAG}$ TC(C/T)TTGTC 3}

Fig. 1. Amino acid sequence of peptides obtained from a 34-kDa glycoprotein elicitor (CBEL) and deduced nucleotide probes. A, Amino acid sequence of the $\mathrm{N}$ terminus ( $\mathrm{N}$ term.) and of peptides (Pep1, Pep2) obtained after trypsin digestion. $\mathrm{X}$ stands for unidentified amino acids. B, Nucleotide sequence of oligonucleotide primers corresponding to the numbered underlined amino acid sequences shown in $\mathbf{A}$. by amino acid sequencing. In order to obtain a specific probe without $\lambda$ ZapII sequences, a second PCR with $34.15 \mathrm{C}$ and a non-degenerate primer, 34N5, (Fig. 1B) corresponding to the amino terminal sequence was carried out. The 541-bp product that was obtained was cloned in pGEM-T and, after confirmation of its identity by partial sequencing, used as a probe for screening the cDNA library of $P$. parasitica var. nicotianae race 0 . After three rounds of screening, 10 positive clones were analyzed by PCR with the primers T3 + T7 and 34N5 + 34.15C, respectively. Five of these clones resulted in a PCR product of ca. $1 \mathrm{~kb}$ with $\mathrm{T} 3+\mathrm{T} 7$ primers, and of ca. $540 \mathrm{bp}$ with primers $34 \mathrm{~N} 5$ and $34.15 \mathrm{C}$. One clone of this homogenous group was subjected to in vivo excision of the pBluescript recombinant plasmid, and sequenced.

As shown in Figure 2, the open reading frame of this clone encodes a 268 amino acid polypeptide with a putative 18residue signal peptide, followed by the amino terminal sequence of the mature polypeptide, whose expected molecular mass and $\mathrm{pI}$ are $26 \mathrm{kDa}$ and 5.9, respectively. The most abundant amino acids are $\operatorname{Thr}(12.7 \%)$, Ser $(9.3 \%)$, Gly (9.3\%), Ala $(9.0 \%)$, Cys $(9.0 \%)$, and Pro $(8.6 \%)$. The sequences of Pep1 and Pep2 are localized at positions 182 to 194 and 242 to 250, respectively (Fig. 2A). Thus, the isolated cDNA clone corresponds to CBEL, with the sequence of Pep2 located at the carboxy terminus of the polypeptide. One single gene seems to encode CBEL in $P$. parasitica var. nicotianae, since Southern blot analysis on genomic DNA showed one band after digestion with restriction enzymes that do not cut in the sequence, and two bands after digestion with NcoI, which cuts once (Fig. 3). The fact that digestion with PstI, which also cuts only once in the cDNA and in the genomic sequence (data not shown), resulted in three bands, might indicate the existence of two alleles in the diploid fungus.

Examination of the amino acid sequence of this clone uncovered several striking features: (i) the deduced mature polypeptide comprises two repeated domains (amino acids 1 to 115 and 138 to 250) that can be aligned after introduction of one amino acid gap, and show $54.4 \%$ identity and $90.4 \%$ homology to each other (Fig. 2B); (ii) each such domain contains 12 cysteine residues at conserved positions, with two cysteine doublets per domain (Fig. 2B); (iii) the two repeated domains are separated by a threonine/proline-rich region in which the residues are organized in a palindromic manner around a central methionine (Fig. 2C); and (iv) the high proportion of serine and threonine $(22 \%)$, which are potential sites for O-glycosylation, together with the presence of a putative N-glycosylation site (Asn-X-Ser/Thr) located at position 166 , is in agreement with the relatively high glycosylation level, accounting for ca. $50 \%$ of the glycoprotein (SéjalonDelmas et al. 1997).

\section{Biological properties.}

As a whole, no significant homology between this clone and published sequences could be detected in data banks with the BLAST program. However, additional information was gained by analyzing each domain separately. Thus, the Thr/ Pro region is reminiscent of sequences present in glycanases that bind cellulose (Gilkes et al. 1991). These enzymes are generally composed of a cellulose-binding domain (CBD) and a catalytic domain joined via a Thr/Pro hinge region. Since CBDs are cysteine-rich, we compared the two cysteine-rich 
domains of CBEL to known fungal CBDs. This analysis revealed that each repeated domain of the polypeptide contains the motif C-G-S-x(3)-G-x(3)-C-x(5)-C-(3)-N-x-x-Y-x-Q-Cand C-G-S-x(2)-G-x(3)-C-x(5)-C-x(3)-N-x-x-x-x-Q-C-, which closely resemble the fungal CBD consensus pattern $\mathrm{C}-\mathrm{G}-\mathrm{G}-$ $x(4)-G-x(3)-C-x(5)-C-x(3)-N-x-[Y W]-Y-x-Q-C-$ (Fig. 4) in which spacing between cysteines is conserved. Thus, the glycoprotein of Phytophthora might have glycan-binding or glycanase activities. These hypotheses were tested in the following experiments.

\section{Glycan-binding activity.}

The function of the putative CBD of CBEL was assayed toward fibrous cellulose, and a cell wall preparation obtained from tobacco roots (Fig. 5). The glycoprotein (62 or $124 \mathrm{ng}$ ) was incubated in $20 \mu \mathrm{l}$ of a $2 \%$ cellulose or cell wall suspension for $1 \mathrm{~h}$ at $25^{\circ} \mathrm{C}$. The soluble and insoluble fractions (i.e., supernatant and pellet) were then analyzed by sodium dodecyl sulfate-polyacrylamide gel electrophoresis (SDS-PAGE) for the presence of CBEL. For this purpose, the pellet was resuspended in the electrophoresis sample buffer, resulting in solubilization of bound glycoprotein. Experiments performed with cellulose (Fig. 5A) show that at low dose in the assay (62 ng, i.e., $90 \mathrm{nM}$ ), CBEL was recovered in the pellet (lane 6) and none remained in the supernatant (lane 5), while at a higher dose (124 ng, i.e., $180 \mathrm{nM}$ ) part of it was found in the supernatant, as shown by the faint band that was observed (lane 2). The amount of cellulose-bound CBEL appeared equivalent in the two assays, which suggests saturation of cellulose. Control assays were performed with ovalbumin or pure cellobiohydrolase II from Trichoderma reesei instead of the elicitor. Ovalbumin did not significantly bind to cellulose, whereas cellobiohydrolase, which possesses a typical CBD (Fig. 4), showed a binding similar to that of the elicitor (data not

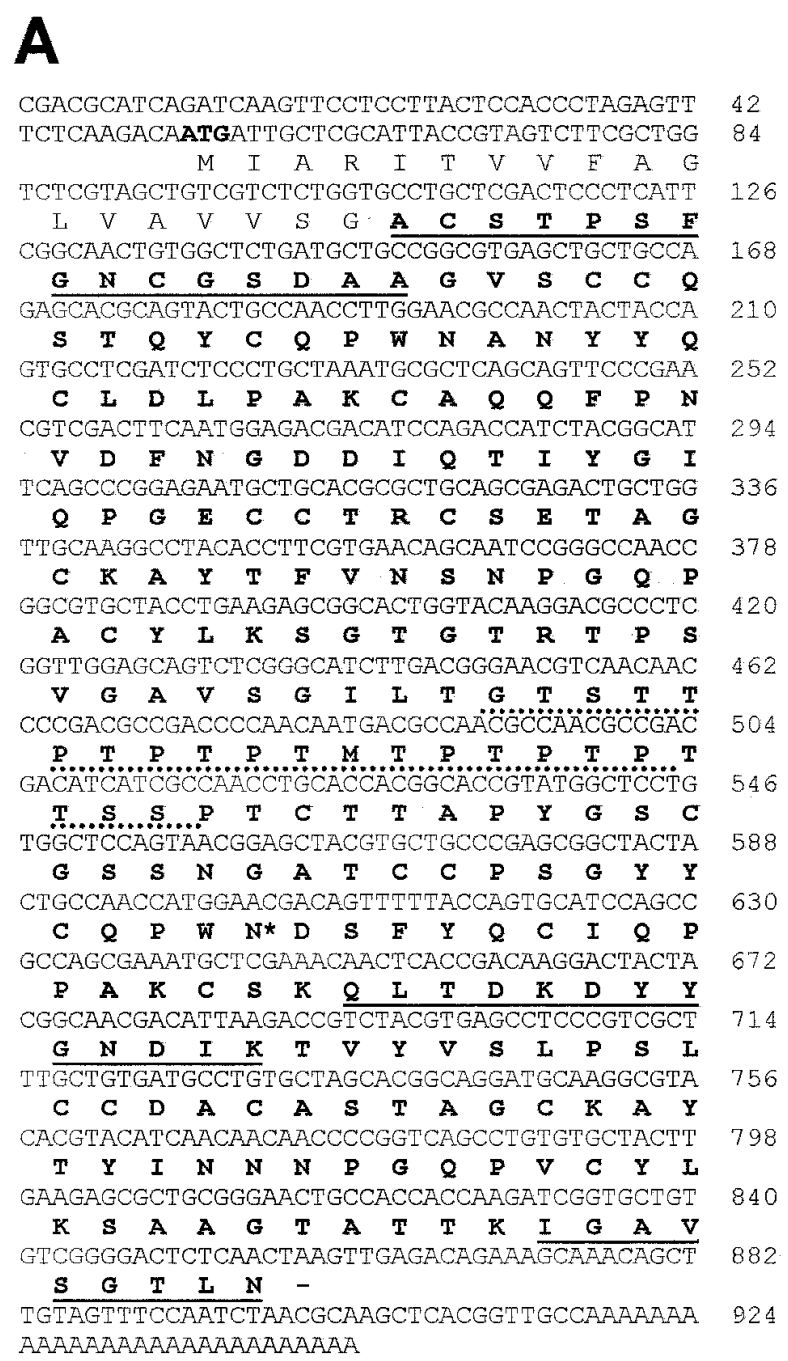

Fig. 2. Nucleotide and deduced amino acid sequence of the cDNA clone. A, Start codon ATG and amino acid sequence of the mature polypeptide are indicated in bold. Sequences of the N terminus, Pep1, and Pep2 are underlined. The Thr/Pro-rich linker separating the peptide in two homologous domains is indicated by a dotted line. The putative N-glycosylation site (N-D-S) is marked by an asterisk. The nucleotide sequence has been submitted to the EMBL Data Library under the accession number X97205. B, Sequence comparison of the two homologous domains located between amino acids 1 and 114, and 138 to 250 , respectively; the conserved amino acids are in black boxes. $\mathbf{C}$, The threonine/proline-rich region located between amino acids 115 and 137; arrows underline the palindromic sequence organized around a single central methionine. 
shown). In similar experiments with tobacco root cell walls, again a substantial proportion of CBEL was retained in the cell wall pellet (Fig. 5B). At the amount of $31 \mathrm{ng}$ (i.e., $45 \mathrm{nM}$ ) apparently all glycoprotein bound to the cell wall, since no band was detected in the supernatant (lane 5), whereas at

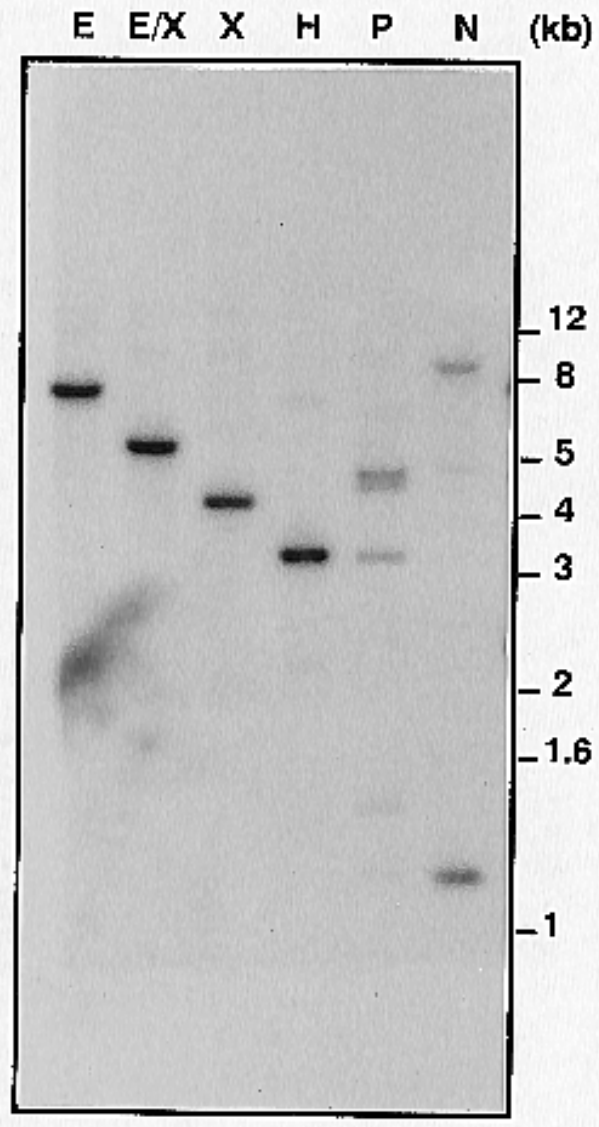

Fig. 3. Southern blot analysis of Phytophthora parasitica var. nicotianae genomic DNA. DNA $(10 \mu \mathrm{g})$ was digested with EcoRI (E), XhoI (X), $E c o \mathrm{RI}+X h o \mathrm{I}(\mathrm{E} / \mathrm{X}), \operatorname{Hind} \mathrm{III}(\mathrm{H}), P s t \mathrm{I}(\mathrm{P})$, or $N c o \mathrm{I}(\mathrm{N})$, subjected to agarose gel electrophoresis and transfer onto a nylon membrane. The membrane was hybridized with the radioloabeled insert of the 34-kDa glycoprotein elicitor (CBEL) cDNA clone and exposed to an X-ray film.

PcCbhI
TrCbhI
TrCbhII
TrEglII
TrEglIII
PpnD1
PpnD2

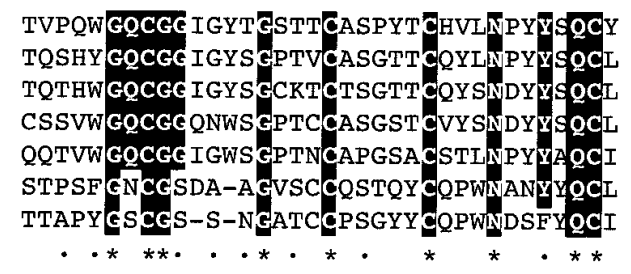

Fig. 4. Sequence comparison of fungal cellulose-binding domains (CBDs) and the two conserved domains of the 34-kDa glycoprotein elicitor (CBEL). Alignment of CBD sequences of fungal glycanases (reviewed by Gilkes et al. 1991) and of the two cysteine-rich sequences present in the first (PpnD1) and second (PpnD2) domains of the Phytophthora glycoprotein. Alignment was achieved by the CLUSTAL program of PC/Gene (IntelliGenetics, Geneva). Conserved amino acids appear in black boxes and are marked by an asterisk. Other relatively conserved residues are indicated by a dot. Pc, Phanerochaete chrysosporium; Ppn, Phytophthora parasitica var. nicotianae; Tr, Trichoderma reesei; Cbh, cellobiohydrolase; Egl, endoglucanase. higher doses part of it was detected in this fraction (lane 2). The faint band of smaller molecular mass in lane 4 is an artifact probably arising from repeated freeze-thaw cycles of the same sample of the pure glycoprotein, since it was not observed in former assays. Thus, CBEL binds to cellulose and plant cell walls. In the latter case binding might be mediated by the cellulose fibrils, which account roughly for one third of the plant cell wall dry weight.

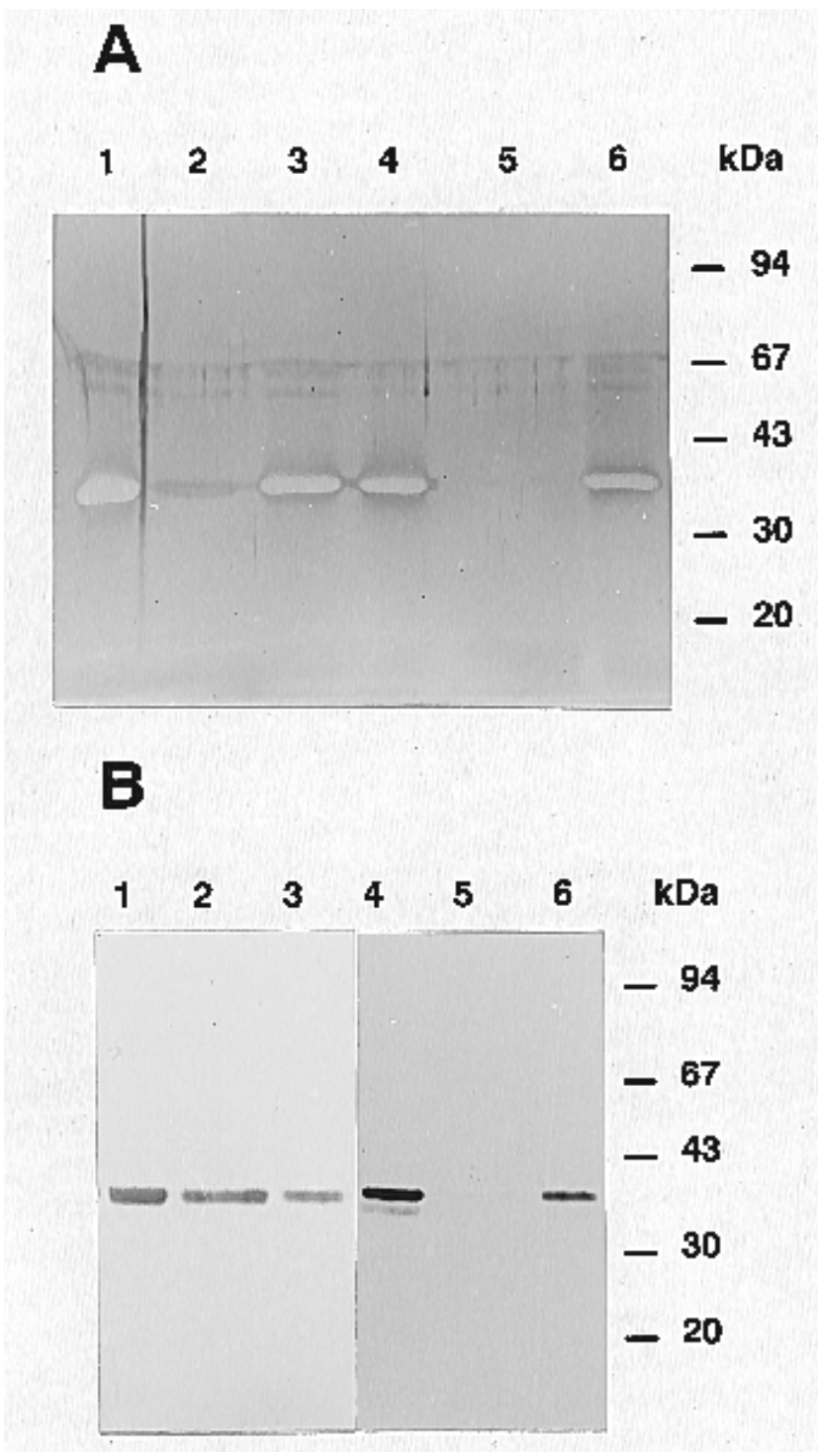

Fig. 5. Cellulose- and cell wall-binding activity of the 34-kDa glycoprotein elicitor (CBEL). The glycoprotein (124 or $62 \mathrm{ng}$ ) was incubated with $400 \mathrm{ng}$ of cellulose or $400 \mathrm{ng}$ of tobacco root cell wall. The supernatant and solubilized cellulose extracts or cell wall extracts were analyzed by sodium dodecyl sulfate-polyacrylamide gel electrophoresis. Molecular marker size is indicated at right. A, Silver staining of CBEL recovered after incubation with cellulose; due to its glycosylation, band appears negatively stained. Assays were performed with 124 (lanes 1 to 3) or $62 \mathrm{ng}$ (lanes 4 to 6) of the glycoprotein. Controls (lanes 1 and 4) represent CBEL without prior incubation. Lanes 2 and 5 correspond to the supernatant, lanes 3 and 6 to the fraction solubilized from cellulose. B, Western blot (immunoblot) analysis of CBEL recovered after incubation with tobacco cell walls. Assays were performed with 62 (lanes 1 to 3 ) or $31 \mathrm{ng}$ (lanes 4 to 6) of glycoprotein. Lanes 1 and 4 correspond to controls without prior incubation. Lanes 2 and 5 represent the supernatant after incubation of CBEL with cell walls; lanes 3 and 6 the fraction solublilized from the cell walls. 
In order to detect a possible hydrolytic activity, CBEL $(1 \mu \mathrm{g}$ of protein) was incubated with $2.5 \mu \mathrm{g}$ of CM-cellulose, cellobiose, cellopentaose, xylan, laminarin, or chitin. After 1 to 20 $\mathrm{h}$ of incubation, the reaction mixture was analyzed by DionexHPLC for the presence of hydrolysis products. No such products could be detected, indicating that CBEL had no glycolytic activity on these substrates under the experimental conditions.

\section{Hemagglutination activity.}

The structural organization of the polypeptide in homologous domains, together with the sugar-binding capacity, are common features of lectins. In order to check whether CBEL had lectin-like activity, it was used in an agglutination assay with human red blood cells. Cells were readily agglutinated by the glycoprotein at a concentration as low as $1.55 \mu \mathrm{g} / \mathrm{ml}$, i.e., $45 \mathrm{nM}$. Hapten inhibition assays were performed with a series of sugar monomers (D-glucose, Dgalactose, D-mannose, L-fucose, L-rhamnose, D-arabinose, D-xylose, D-glucosamine, D-galactosamine, $N$-acetyl Dgalactosamine, and $N$-acetyl D-glucosamine) and with cellobiose and CM-cellulose. None of these sugar compounds competed for binding. Similar assays performed with fetuin, an animal glycoprotein often used for lectin purification, resulted in inhibition of agglutination; $20 \mu \mathrm{M}$ of fetuin was required to inhibit agglutination by $750 \mathrm{nM}$ CBEL. These results suggest that the Phytophthora glycoprotein behaves as a new fungal lectin.

\section{Elicitor activity.}

In order to characterize the elicitor activity, CBEL was injected into the main leaf vein of tobacco plants, cultivar 46-8 (15 pmol per injection, i.e., $150 \mathrm{nM})$. After 4 to $5 \mathrm{~h}$, the infiltrated areas appeared shiny. Two to 3 days afterward, these zones became necrotic (data not shown) and fluoresced under UV light, suggesting accumulation of phenolic compounds. Necroses were strictly limited to the infiltrated areas and only rarely covered the whole area. Leaf tissues corresponding to the infiltrated zone were analyzed for expression of genes encoding lipoxygenase (LOX), sesquiterpene cyclase (EAS), chitinase $(\mathrm{CHN})$ and $\beta-1,3$ glucanase (GLU). It is widely accepted that LOX is involved in signal transduction leading to defense, while the three other proteins participate in the defense of tobacco. Expression of the four genes, which was very low or undetectable in control tissues infiltrated with water, was highly enhanced in response to infiltration with the glycoprotein (Fig. 6B). A time course study showed that LOX was expressed earlier than the other genes. LOX transcripts appeared within the first $4 \mathrm{~h}$ after infiltration and their level was maximum at $12 \mathrm{~h}$. Induction of LOX was accompanied, although with some delay, by the appearance of EAS transcripts and both were followed by CHN and GLU gene expression. Maximum expression was reached at 8 to $12 \mathrm{~h}$ for EAS and at $48 \mathrm{~h}$ for the two PR proteins.

Thus, CBEL is a potent elicitor that induces necrosis and defense in tobacco at a concentration of $150 \mathrm{nM}$. In order to evaluate the biological significance of its activity, additional experiments combined elicitor treatment and inoculation with the fungus. For this purpose, the apex of tobacco plants was cut off and a drop containing 150 pmol of the elicitor was applied to the surface. Two days later, the plants were stem inoculated with a piece of mycelium of the virulent race 1 of $P$.
A

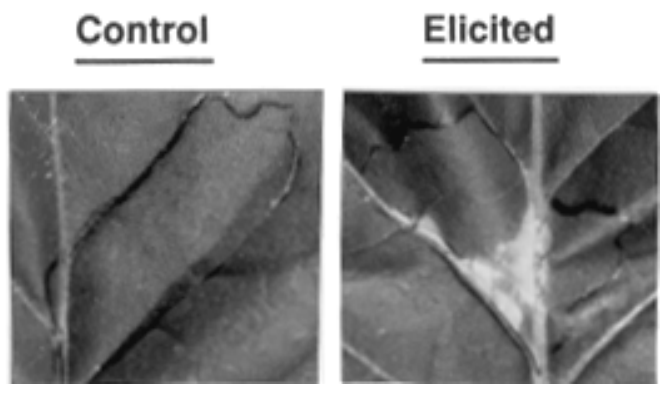

B

\section{Control Elicited}

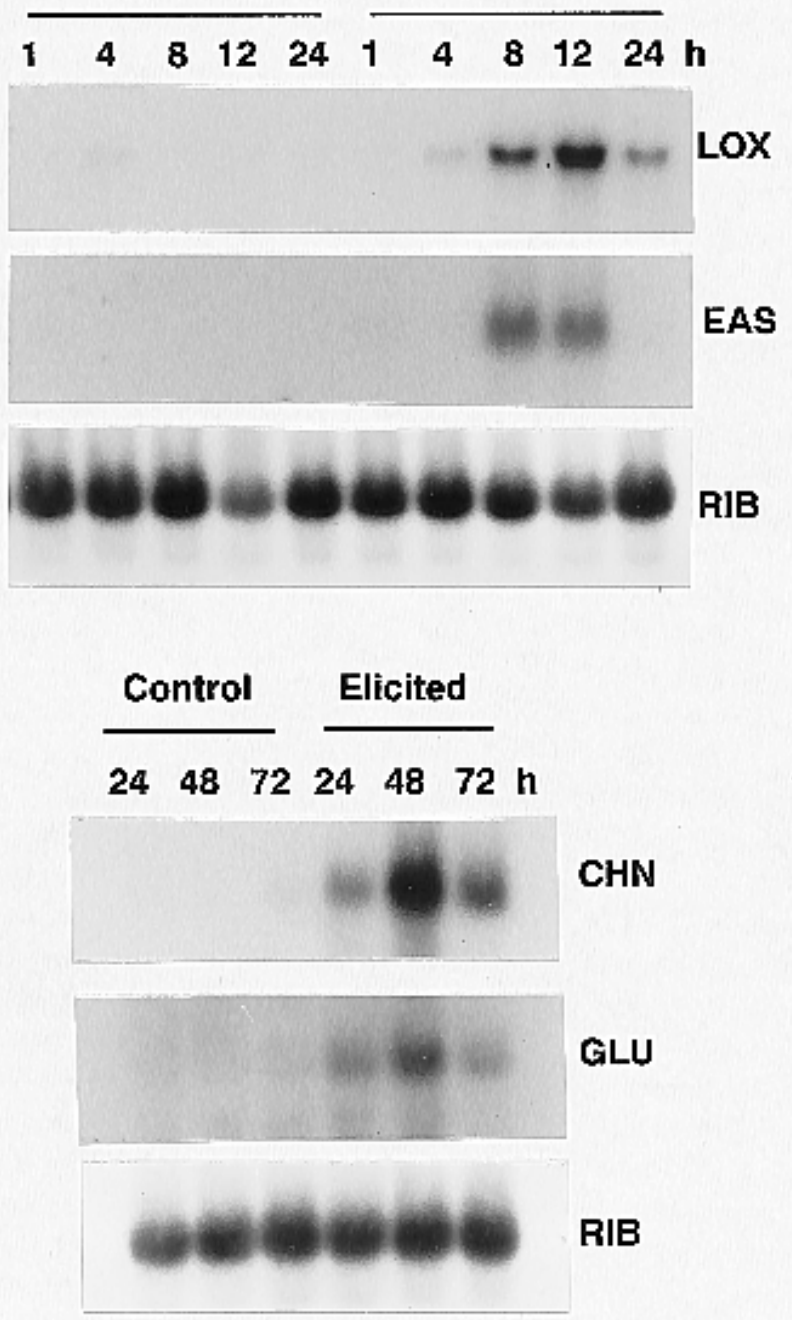

Fig. 6. Elicitor activity of the 34-kDa glycoprotein elicitor (CBEL). The glycoprotein (500 ng, i.e., $15 \mathrm{pmol}$ ) dissolved in $100 \mu \mathrm{l}$ of distilled water was injected into the main vein of the third leaf of 3-month-old tobacco plants. Control plants were infiltrated with water. A, Necrosis was photographed 4 days after infiltration; black line marks limits of the infiltrated area. B, RNA was extracted after infiltration at times indicated. Total RNA $(10 \mu \mathrm{g})$ was subjected to denaturing electrophoresis in a formaldehyde-agarose gel, transferred to a nylon membrane, and hybridized with radiolabeled probes corresponding to tobacco lipoxygenase (LOX), sesquiterpene cyclase (EAS), chitinase $(\mathrm{CHN}), \beta-1,3$ glucanase (GLU), and 18S rDNA (RIB). 
parasitica var. nicotianae. Symptoms became visible after 4 days when plants had been pretreated with water, whereas elicitor-pretreated plants were protected against disease development (Fig. 7). From these experiments, it can be concluded that CBEL is a highly active elicitor that induces efficient defense mechanisms in the host plant.

\section{DISCUSSION}

We have isolated a cDNA that corresponds to the peptide moiety of a previously identified cell wall glycoprotein from Phytophthora parasitica var. nicotianae endowed with elicitor activity (Séjalon et al. 1995; Séjalon-Delmas et al. 1997). The presence of a signal peptide and of a putative N-glycosylation site and high amounts of Ser and Thr (22\%), as well as the calculated molecular mass $(26 \mathrm{kDa})$ of the product, are consistent with the previously reported cell wall localization and apparent molecular mass $(34 \mathrm{kDa})$ of this glycoprotein, now designated as CBEL. The peptide does not seem to be processed by proteases since the $\mathrm{C}$ terminus corresponds to Pep2, one of the sequenced peptides. Analysis of the deduced peptide sequence by the method of Argos et al. (1982) reveals the existence of a putative transmembrane helix at the C-terminal end. This might be correlated to the observation that immunogold labeling of the glycoprotein, though mainly in the cell wall, was in part associated to the cell wall-plasma membrane interface (Séjalon-Delmas et al. 1997).

A detailed analysis of the nucleotide and derived amino acid sequences of the cDNA indicated several novel and interesting features, both structural and functional. The first striking feature resides in the structural organization of the molecule, which comprises two repeated, homologous cysteine-rich domains of 114 and 113 amino acids, respectively, connected by a Thr/Pro-rich linker that is itself made of two inverted repeats organized in a palindromic manner. Assuming that some Cys residues are engaged in disulfide bridges, one might predict that the molecule is composed of two heads held together by a

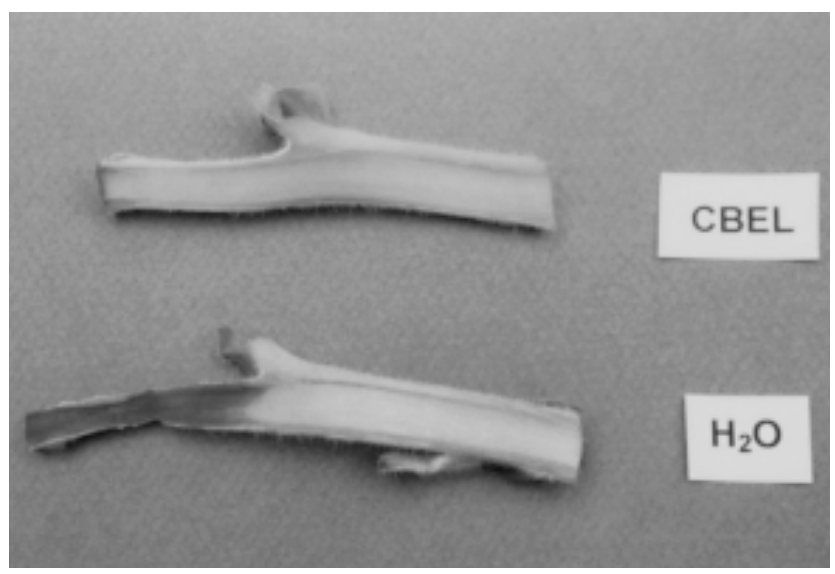

Fig. 7. Effect of elicitor pretreatment on susceptibility of tobacco toward Phytophthora parasitica var. nicotianae. Apex of 4-month-old tobacco plant was cut off and the glycoprotein $(5 \mu \mathrm{g}$, i.e., $150 \mathrm{pmol})$ dissolved in $60 \mu \mathrm{l}$ of distilled water was applied to the cut surface (CBEL). After 2 days, the plants were inoculated on the same surface with a piece of mycelium of Phytophthora parasitica var. nicotianae race 1, virulent on this tobacco line. Symptoms were observed 4 to 5 days later. Control plants were pretreated with water before inoculation $\left(\mathrm{H}_{2} \mathrm{O}\right)$. hinge region. The high cysteine content of CBEL might indicate a functional relationship to other cysteine-rich proteins from animals, plants, and fungi that have a role in cellular interactions (reviewed by Templeton et al. 1994), notably the necrosis-inducing peptides of Cladosporium fulvum (AVR9, AVR4) and Rhynchosporium secalis (NIP1), and the elicitins of various Phytophthora spp. (Van den Ackerveken et al. 1992; Joosten et al. 1994; Rohe et al. 1995; Yu 1995). It has been observed that the necrosis-inducing activity of AVR4 and AVR9 depends on the occurrence of Cys residues at specific locations (De Wit et al. 1996). Some of the Cys residues of NIP1 occur as doublets, as in the case of the peptide moiety described in this work. Despite these resemblances, the presence of the two repeated domains clearly distinguishes the molecule of $P$. parasitica var. nicotianae from all these elicitors that contain only one stretch of Cys-rich sequences. It is likely that similar molecules occur in other Phytophthora spp., since hybridizing bands were detected in Southern blots with genomic DNA of several Phytophthora (data not shown).

The second-most striking feature resides in the functional properties of CBEL. The data showed that the molecule is a potent elicitor that induces necrosis and defense gene expression in the tobacco-Phytophthora interaction. The time course of gene induction is comparable to results described for defense gene induction in tobacco after leaf infiltration with an elicitor from P. megasperma (Baillieul et al. 1995) or treatment of a cell suspension with cell wall fragments from $P$. parasitica var. nicotianae (Rickauer et al. 1997). The elicitor activity of CBEL was further confirmed by its protective effect against subsequent inoculation with the virulent race 1 of $P$. parasitica var. nicotianae. Preliminary experiments showed that a homologue of CBEL is also produced by this race of the fungus (data not shown), but its biological activities have not been studied yet. It has been demonstrated by immunocytolocalization that CBEL is present at the surface of the fungus during invasion of the host plant, and that this presence could be detected earlier in the incompatible interaction than in the compatible one (Séjalon-Delmas et al. 1997). Thus, by differential production in a resistant or susceptible host, CBEL might play a role in the outcome of the interaction.

A major aspect of our work was to show that the elicitor binds to crystalline cellulose in a dose-dependent manner. This property was deduced from sequence homology of each Cys-rich domain to the CBDs found in cellulases from various fungi (Gilkes et al. 1991). In contrast to cellulases, however, the elicitor did not show detectable enzyme activity. Instead, the elicitor behaves as a lectin. This property is consistent with the two repeated domains and the glycan-binding activity of the molecule. Chitin-binding domains have been reported for a number of plant lectins (Chrispeels and Raikhel 1991), but to our knowledge this is the first lectin with a CBD. Whether the same binding sites account for cellulose binding and hemagglutination will be investigated in future work.

The glycan-binding property of CBEL was fully confirmed by its affinity for tobacco cell walls. The possibility that a microbial elicitor might act through its interaction with the plant cell wall, rather than with binding sites in the plasma membrane, has been proposed recently for the harpin elicitor from Pseudomonas syringae pv. syringae (Hoyos et al. 1996). These results, together with our data, might illustrate the concept that the extracellular matrix and the cytoskeleton of plant 
cells form an interactive scaffold for perception and transduction of information (Wyatt and Carpita 1993).

Altogether, the data gained throughout these studies show for the first time the multifunctional properties of a fungal elicitor formerly called GP34 (Séjalon-Delmas et al. 1997). All these activities were observed within roughly the same concentration range. According to its cellulose-binding, elicitor, and lectin-like activities, we adopted the abbreviation CBEL for this glycoprotein. So far, very few cell wall proteins and their corresponding genes or cDNA have been isolated from fungi, and none with elicitor activity. Although a function in cell wall structure cannot be excluded, the three activities encountered in CBEL suggest that the glycoprotein might have a role in the attachment of the fungus on the host surface. However, this interaction also leads to strong defense responses in the host plant. Thus, CBEL might illustrate the concept that microbial elicitors, although conferring undesirable traits, would have been maintained during evolution because they fulfill general functions that are beneficial to other aspects of the life cycle of microorganisms. Future work will be aimed at investigating the respective roles of the CBDs and of the glycan portion of CBEL. Studies on the possible implication of this glycoprotein in the race-cultivar specific interaction between tobacco and $P$. parasitica var. nicotianae, and on the occurrence of CBEL in other fungal species, are under way.

\section{MATERIALS AND METHODS}

\section{Biological material.}

Phytophthora parasitica Dastur var. nicotianae races 0 and 1 were maintained on oat meal agar at $25^{\circ} \mathrm{C}$ in the dark. For liquid culture of the fungus, the mycelium was grown in the dark at $25^{\circ} \mathrm{C}$ for 14 days on the synthetic medium described by Keen (1975). The mycelium was harvested by gentle filtration, washed, and stored at $-20^{\circ} \mathrm{C}$.

Tobacco plants (Nicotiana tabacum L.), cultivar 46-8, were grown on vermiculite in a growth chamber with a photoperiod of $12 \mathrm{~h}$ light at $140 \mu \mathrm{E} \mathrm{s}^{-1} \cdot \mathrm{m}^{-2}$ and $25^{\circ} \mathrm{C}$, and $12 \mathrm{~h}$ dark at $18^{\circ} \mathrm{C}$. This cultivar is resistant to race 0 and susceptible to race 1 of the fungus (Helgeson et al. 1972).

\section{Isolation of elicitor and sequencing of derived peptides.}

The 34-kDa glycoprotein (CBEL) was purified from the mycelium of Phytophthora parasitica var. nicotianae race 0 by cation exchange chromatography and gel filtration chromatography as described previously (Séjalon-Delmas et al. 1997). Protein measurement was performed with the Bio-Rad protein reagent according to the supplier's instructions (BioRad, Ivry sur Seine, France), with bovine serum albumin (BSA) as standard protein.

Prior to trypsin digestion, the glycoprotein $(30 \mu \mathrm{g})$ was electrophoresed on an SDS polyacrylamide gel. Digestion was then achieved by incubating a slice of the gel containing the glycoprotein with trypsin at $30^{\circ} \mathrm{C}$ according to Rosenfeld et al. (1992). Peptides were eluted from the gel by four washes, each in $100 \mu \mathrm{l}$ of $50 \%$ acetonitrile, $0.5 \%$ trifluoroacetic acid (TFA), for $20 \mathrm{~min}$ at $30^{\circ} \mathrm{C}$. Samples were dried under vacuum in a speed vac concentrator before being dissolved in $10 \mu \mathrm{l}$ of $50 \%$ acetonitrile and $90 \mu \mathrm{l}$ of solution A (1.1\% TFA in ultrapure water). They were then purified by HPLC-reversed phase chromatography on a Narrowbore C18-Vydac column (218 TP52: length, $25 \mathrm{~cm}$; diameter, $0.21 \mathrm{~cm}$ ) equilibrated in $99 \%$ solution $\mathrm{A}, 1 \%$ solution $\mathrm{B}$ ( $\mathrm{B}=0.8 \%$ o TFA in acetonitrile). Elution was achieved in $60 \mathrm{~min}$ by a gradient of 1 to $45 \%$ solution $\mathrm{B}$ at $0.3 \mathrm{ml} / \mathrm{min}$.

In order to sequence the $\mathrm{N}$ terminus of the protein moiety, the purified glycoprotein $(3.4 \mu \mathrm{g})$ was subjected to SDSPAGE before being transferred onto a PVDF Immobilon membrane (Bio-Rad), in $50 \mathrm{mM}$ Tris base, $50 \mathrm{mM}$ boric acid at $15 \mathrm{~V}$ overnight. After staining with a solution of $0.1 \%$ Amidoblack in $45 \%$ methanol, $1 \%$ acetic acid, the protein band was cut out and the protein was sequenced directly on the membrane. Sequencing of the amino terminus and of tryptic peptides was performed by automated Edman degradation (Edman and Begg 1967) at the Institut Pasteur-Service (Paris).

\section{Nucleic acid extraction.}

Total RNA was extracted from the powder obtained by grinding the biological material (fungal mycelium or plant tissues) in a mortar with a pestle under liquid nitrogen. Extraction was achieved in a single step with Extract All reagent (Eurobio, Les Ulis, France) at the ratio of $1 \mathrm{ml}$ per $100 \mathrm{mg}$ of material. Poly $(\mathrm{A})^{+}$RNA was prepared from total RNA by chromatography on an oligo(dT) cellulose column (Bio-Rad) according to the supplier's instructions. Genomic DNA was extracted from ground mycelium by the method of Dellaporta et al. (1983). RNA and DNA concentrations were measured spectrophotometrically at $260 \mathrm{~nm}$.

\section{cDNA library construction and screening.}

Double-stranded cDNAs were synthesized from $5 \mu \mathrm{g}$ of poly $(\mathrm{A})^{+}$RNA of $P$. parasitica var. nicotianae race 0 with a $\lambda$ ZapII cDNA cloning kit (Stratagene, Montigny-le Bretonneaux, France) and ligated to EcoRI linkers according to the instructions of the supplier. After kinasing of EcoRI ends and digestion with $\mathrm{XhoI}$, the cDNAs were fractionated on a Sephacryl S-400 column $(5 \times 100 \mathrm{~mm})$. DNA fragments longer than $500 \mathrm{bp}$ were selected for ligation to predigested $\lambda$ ZapII vector arms, and further packaged into phage particles with an in vitro packaging kit (Gigapack II, Stratagene). The initial cDNA library, which consisted of $6.10^{5}$ independent recombinant clones, was amplified in Escherichia coli XL1-Blue (Stratagene).

The amplified cDNA library was screened with a PCR product that was prepared as described below and labeled with $\left[\alpha-{ }^{32} \mathrm{P}\right] \mathrm{dCTP}$ by random priming (Feinberg and Vogelstein 1983). In the first round, $2 \times 10^{5}$ clones were transferred to nylon membranes (Appligene, Illkirch, France) in duplicate and hybridized with this fragment under standard conditions (Sambrook et al. 1989). Membranes were washed under standard stringency conditions $(2 \times \mathrm{SSC}[1 \times \mathrm{SSC}$ is $0.15 \mathrm{M} \mathrm{NaCl}$ plus $0.015 \mathrm{M}$ sodium citrate], $0.1 \% \mathrm{SDS}$ at $65^{\circ} \mathrm{C}$ ), and were exposed to Hyperfilm MP (Amersham, Les Ulis, France) at $-80^{\circ} \mathrm{C}$. Positive plaques were selected and purified by two subsequent rounds of plating and screening, at low density, under the same conditions. The finally selected positive plaque was subjected to in vivo excision of the pBluescript recombinant plasmid from $\lambda$ ZapII according to the instructions of the supplier.

The pBluescript recombinant plasmid DNA was purified with a Qiagen (Paris) plasmid preparation kit and digested 
with EcoRI + XhoI (Appligene), and the products were analyzed by electrophoresis on an $0.8 \%$ agarose gel. Sequencing of the insert was performed by the dideoxy chain termination method according to Sanger et al. (1977). The nucleotide and amino acid sequences were analyzed with a BLAST (Altschul et al. 1990) sequence analysis system.

For PCR experiments, $5-\mu \mathrm{l}$ aliquots of the cDNA library or of an individual clone (i.e., a plaque of phages dissolved in $100 \mu \mathrm{l}$ of distilled water) were first treated at $70^{\circ} \mathrm{C}$ for $5 \mathrm{~min}$. Primers were then added at a final concentration of $0.4 \mu \mathrm{M}$ for universal $\mathrm{T} 3$ and $\mathrm{T} 7$, and $2 \mu \mathrm{M}$ for specific primers, respectively. The reaction mixture was composed of $250 \mu \mathrm{M}$ dNTPs; $1 \mathrm{mM}$ Tris- $\mathrm{HCl} \mathrm{pH} 9.0 ; 5 \mathrm{mM} \mathrm{KCl} ; 150 \mu \mathrm{M} \mathrm{MgCl} 2 ; 20 \mu \mathrm{g}$ of BSA per $\mathrm{ml} ; 0.01 \%$ Triton $\mathrm{X}-100$, and 1 unit Taq DNA polymerase (Appligene) in a total reaction volume of $25 \mu \mathrm{l}$. A first denaturation step at $94^{\circ} \mathrm{C}$ for $5 \mathrm{~min}$ was followed by 35 cycles of PCR $\left(1 \mathrm{~min}\right.$ at $94^{\circ} \mathrm{C}, 1 \mathrm{~min}$ at $60^{\circ} \mathrm{C}, 2 \mathrm{~min}$ at $72^{\circ} \mathrm{C}$ per cycle), and a last elongation step of $10 \mathrm{~min}$ at $72^{\circ} \mathrm{C}$.

\section{Northern (RNA) blot hybridization.}

Northern blot analysis was performed with total RNA (10 $\mu \mathrm{g}$ ) as described previously (Rickauer et al. 1997). The probes used in this study were pTL-35 for lipoxygenase (Véronési et al. 1995), pBS-TEAS for sesquiterpene cyclase (Facchini and Chappell 1992), pNT517 for glucanase (Godiard et al. 1990), and pCHN50 for chitinase (Shinshi et al. 1987), kindly provided by the respective authors. The corresponding inserts were released by digestion with the appropriate restriction enzymes, purified on glass beads after agarose gel electrophoresis with a Geneclean kit (Ozyme, Montigny-le Bretonneaux, France), and labeled by random priming (Feinberg and Vogelstein 1983). Hybridization with a PCR fragment corresponding to $18 \mathrm{~S}$ rDNA was performed in order to check that equal amounts of RNA had been loaded. Each experiment, including sample preparation and RNA isolation, was carried out two or three times independently.

\section{Southern blot hybridization.}

Genomic DNA $(10 \mu \mathrm{g})$ was digested by appropriate restriction enzymes (Appligene) according to the supplier's instructions and the fragments were separated by electrophoresis on a $1 \%$ agarose gel. After alkaline denaturation the DNA was transferred to a neutral nylon membrane (Sambrook et al. 1989 ), and fixed by baking at $80^{\circ} \mathrm{C}$. Prehybridization and hybridization occurred in $5 \times \mathrm{SSC}, 5 \times$ Denhardt's solution, $0.1 \%$ SDS, and $100 \mu \mathrm{g}$ of denatured salmon sperm DNA per ml. The probe, corresponding to the EcoRI-XhoI fragment of the CBEL cDNA clone, was labeled with $\left[\alpha-{ }^{32} \mathrm{P}\right] \mathrm{dCTP}$ by random priming (Feinberg and Vogelstein 1983). The membranes were successively washed in $0.1 \times \mathrm{SSC}, 0.1 \% \mathrm{SDS}$ at $65^{\circ} \mathrm{C}$ and exposed to Hyperfilm MP (Amersham) at $-80^{\circ} \mathrm{C}$.

\section{Elicitor bioassays.}

The elicitor (500 ng) dissolved in $100 \mu \mathrm{l}$ of distilled water was injected into the main vein of the third leaf of 3-monthold tobacco plants; control leaves of the same age were treated with the same volume of water. The infiltrated area was cut out at the times indicated in Results, and total RNA was extracted from the tissue. Expression of defense-related genes was assessed by Northern blot hybridization as described above.

\section{Enzyme assays.}

Enzyme assays were performed in $1 \mathrm{ml}$ of sodium acetate buffer, $100 \mathrm{mM}$, pH 5.0 for 1 to $20 \mathrm{~h}$ at $50^{\circ} \mathrm{C}$ in the presence of $0.1 \%$ substrate (Sigma, St. Quentin, France) and $1 \mu \mathrm{g}$ of the glycoprotein. After incubation, the resulting solution was analyzed for the presence of sugars on a Dionex-HPLC system (Sunnyvale, CA) equipped with a Carbo Pac PA1 (10-32) analytical column as already described (Roux et al. 1994).

\section{Cellulose-binding assays.}

The cellulose-binding assay was modified from the protocol described by Shoseyov and Doi (1990). Samples of CBEL were incubated for $1 \mathrm{~h}$ at room temperature in $20 \mu \mathrm{l}$ of 100 $\mathrm{mM} \mathrm{Na}$ acetate buffer $\mathrm{pH} 5.0$, containing $2 \%$ fibrous cellulose (CF11, Whatman) or $2 \%$ cell walls prepared from tobacco roots as described by Roux et al. (1994). After centrifugation of the suspension, the pellet (i.e., cell walls) and supernatant were separately recovered, and the pellet was washed three times with fresh incubation buffer. The supernatant and the washed pellet were each mixed with electrophoresis sample buffer, denatured at $100^{\circ} \mathrm{C}$, and analyzed for the presence of CBEL by SDS-PAGE, performed according to Laemmli (1970) with a $12 \%$ resolving gel and a $3 \%$ stacking gel. Proteins were either stained with silver nitrate as described by Oakley et al. (1980) or revealed with a polyclonal antiserum directed against CBEL as described by Séjalon-Delmas et al. (1997), after transfer onto a nitrocellulose membrane. Molecular mass standards were purchased from Pharmacia (St. Quentin, France), and ovalbumin from Sigma, and Trichoderma reesei cellobiohydrolase was obtained from Cayla (Toulouse, France).

\section{Hemagglutination assays.}

Hemagglutination assays were carried out in microtiter plates in a final volume of $200 \mu \mathrm{l}$. CBEL $(150 \mu \mathrm{l})$ dissolved in $100 \mathrm{mM} \mathrm{Na}$ phosphate buffer, $\mathrm{pH} 7.2,9 \%$ o NaCl, was mixed with $50 \mu \mathrm{l}$ of a $2 \%$ suspension of red blood cells $(0 \mathrm{Rh}+)$ in the same buffer. The glycoprotein $(10 \mu \mathrm{g}$ in the first well) was serially diluted with twofold increments. Agglutination was scored by visual examination of the red blood cell suspension, after $1 \mathrm{~h}$ at room temperature (ca. $25^{\circ} \mathrm{C}$ ).

For competition assays, fetuin, cellobiose, carboxymethylcellulose, and a series of sugar monomers (all compounds from Sigma) were employed. Final concentrations of fetuin, sugars, and CM-cellulose were, respectively, $20 \mu \mathrm{M}, 200 \mathrm{mM}$, and $0.67 \mathrm{mg} / \mathrm{ml}$ before addition of red blood cells.

\section{ACKNOWLEDGMENTS}

We wish to thank P. Sanchez for skilled technical assistance, C. Lafitte for Dionex-HPLC analysis, G. Borderies for HPLC peptide separation, and G. Putinier for typing the manuscript. Trichoderma cellobiohydrolase II was a generous gift from M. Parich (Cayla Co., Toulouse, France).

\section{LITERATURE CITED}

Altschul, S. F., Gish, W., Miller, W., and Lipman, D. J. 1990. Basic local alignment tool. J. Mol. Biol. 215:403-410.

Argos, P., Rao, J. K., and Hargrave, P. A. 1982. Structural prediction of membrane-bound proteins. Eur. J. Biochem. 128:565-575.

Ayers, A. R., Ebel, J., Valent, B., and Albersheim, P. 1976. Host-pathogen interactions: X. Fractionation and biological activity of an elicitor 
isolated from the mycelial walls of Phytophthora megasperma var. sojae. Plant Physiol. 57:760-765.

Baillieul, F., Genetet, I., Kopp, M., Saindrenan, P., Fritig, B., and Kauffmann, S. 1995. A new elicitor of the hypersensitive response in tobacco: A fungal glycoprotein elicits cell death, expression of defence genes, production of salicylic acid, and induction of systemic acquired resistance. Plant J. 8:551-560.

Chrispeels, M. J., and Raikhel, N. V. 1991. Lectins, lectin genes, and their role in plant defense. Plant Cell 3:1-9.

Dellaporta, S. L., Wood, J., and Hicks, J. B. 1983. A plant DNA minipreparation: Version II. Plant Mol. Biol. Rep. 1:19-21.

De Wit, P. J. G. M., Kooman-Gersmann, M., Vogelsang, R., Joosten, M. H. A. J., Vossen, J. P. M. J., Weide, R. L., Laugé, R., Honée, G., and Vervoort, J. J. M. 1996. Structure-function relation studies on AVR9 and AVR4 elicitors from Cladosporium fulvum. Pages 253-258 in: Biology of Plant-Microbe Interactions. G. Stacey, B. Mullin, and P. M. Gresshoff, eds. International Society for Molecular Plant-Microbe Interactions, St. Paul, MN.

Edman, P., and Begg, G. 1967. A protein sequenator. Eur. J. Biochem. 1:80-91.

Facchini, J. P., and Chappell, J. 1992. Gene family for an elicitorinduced sesquiterpene cyclase in tobacco. Proc. Natl. Acad. Sci. USA 89:11088-11092

Farmer, E. E., and Helgeson, J. P. 1987. An extracellular protein from Phytophthora parasitica var. nicotianae is associated with stress metabolite accumulation in tobacco callus. Plant Physiol. 85:733-740.

Feinberg, A. P., and Vogelstein, B. 1983. A technique for labelling DNA restriction endonuclease fragments to high specific activity. Anal. Biochem. 132:6-13.

Gilkes, N. R., Henrissat, B., Kilburn, D. G., Miller, R. C., Jr., and Warren, R. A. J. 1991. Domains in microbial $\beta$-1,4-glycanases: sequence conservation, function and enzyme families. Microbiol. Rev. 55:303315.

Godiard, L., Ragueh, F., Froissard, D., Leguay, J.-J., Grosset, J., Chartier, Y., Meyer, Y., and Marco, Y. 1990. Analysis of the synthesis of several pathogenesis-related proteins in tobacco leaves infiltrated with water and with compatible and incompatible isolates of Pseudomonas solanacearum. Mol. Plant-Microbe Interact. 3:207-213.

Hahn, M. G. 1996. Microbial elicitors and their receptors in plants. Annu. Rev. Phytopathol. 34:387-412.

Helgeson, J. P., Kemp, J. D., Haberlach, G. T., and Maxwell, D. P. 1972. A tissue culture system for studying disease resistance: The black shank disease in tobacco callus cultures. Phytopathology 62:14391443.

Hoyos, M. E., Stanley, C. M., He, S. Y., Pike, S., Pu, X.-A., and Novacky, A. 1996. The interaction of harpin ${ }_{\text {Pss, }}$, with plant cell walls. Mol. Plant-Microbe Interact. 9:608-616.

Joosten, M. H. A. J., Cozijnsen, T. J., and De Wit, P. J. G. M. 1994. Host resistance to a fungal tomato pathogen lost by a single base-pair change in an avirulence gene. Nature 367:384-386.

Keen, N. T. 1975. Specific elicitors of plant phytoalexin production: Determinants of race specificity in pathogenesis. Science 187:74-75.

Kogel, G., Beissmann, B., Reisener, H. J., and Kogel, K. H. 1988. A single glycoprotein from Puccinia graminis f.sp. tritici cell walls elicits the hypersensitive lignification response in wheat. Physiol. Mol. Plant Pathol. 33:173-185.

Laemmli, U. K. 1970. Cleavage of structural proteins during the assembly of the bacteriophage T4. Nature 227:680-685.

Oakley, B. R., Kirsch, D. R., and Morris, N. R. 1980. A simplified ultrasensitive silver stain for detecting proteins in polyacrylamide gels. Anal. Biochem. 105:361-363.

Parker, J. E., Schulte, W., Hahlbrock, K., and Scheel, D. 1991. An extracellular glycoprotein from Phytophthora megasperma f. sp. glycinea elicits phytoalexin synthesis in cultured parsley cells and protoplasts. Mol. Plant-Microbe Interact. 4:19-27.

Ricci, P., Bonnet, P., Huet, J. C., Sallantin, M., Beauvais-Cante, F., Bru- neteau, M., Billard, N., Michel, G., and Pernollet, J. C. 1989. Structure and activity of proteins from pathogenic fungi Phytophthora eliciting necrosis and acquired resistance in tobacco. Eur. J. Biochem. 183:555-563.

Rickauer, M., Brodschelm, W., Bottin, A., Véronési, C., Grimal, H., and Esquerré-Tugayé, M. T. 1997. The jasmonate pathway is involved differentially in the regulation of different defence responses in tobacco cells. Planta 202:155-162.

Rohe, M., Gierlich, A., Hermann, H., Hahn, M., Schmidt, B., Rosahl S., and Knogge, W. 1995. The race-specific elicitor, NIP1, from the barley pathogen, Rhynchosporium secalis, determines avirulence on host plants of the Rrs1 resistance genotype. EMBO J. 14:4168-4177.

Rosenfeld, J., Capdevielle, J., Guillemot, J. C., and Ferrara, P. 1992. In gel digestion of proteins for internal sequence analysis after one or two dimensional gel electrophoresis. Anal. Biochem. 203:173-179.

Roux, C., Mazau, D., Rickauer, M., Fournier, J., Berthalon, E., and Esquerré-Tugayé, M. T. 1994. Hydroxyproline-containing fragments in the cell wall of Phytophthora parasitica. Phytochemistry 35:591595.

Sambrook, J., Fritsch, E. F., and Maniatis, T. A. 1989. Molecular Cloning: A Laboratory Manual. 2nd ed. Cold Spring Laboratory, Cold Spring Harbor, NY.

Sanger, F., Miklen, S., and Coulson, A. R. 1977. DNA sequencing with chain-terminating inhibitors. Proc. Natl. Acad. Sci. USA 74:54635467.

Schottens-Toma, I. M. G., and De Wit, P. J. G. M. 1988. Purification and primary structure of a necrosis-inducing peptide from the apoplastic fluids of tomato infected with Cladosporium fulvum (syn. Fulvia fulva). Physiol. Mol. Plant Pathol. 33:59-67.

Séjalon, N., Villalba, F., Bottin, A., Rickauer, M., Dargent, R., and Esquerré-Tugayé, M. T. 1995. Characterization of a cell surface antigen isolated from the plant pathogen Phytophthora parasitica var. nicotianae. Can. J. Bot. 73S:1104-1108.

Séjalon-Delmas, N., Villalba Mateos, F., Bottin, A., Rickauer, M., Dargent, R., and Esquerré-Tugayé, M. T. 1997. Purification, elicitor activity, and cell wall localization of a glycoprotein from Phytophthora parasitica var. nicotianae, a fungal pathogen of tobacco. Phytopathology 87:899-909.

Shinshi, H., Mohnen, D., and Meins, F. 1987. Regulation of a plant pathogenesis-related enzyme: Inhibition of chitinase and chitinase mRNA accumulation in cultured tobacco tissues by auxin and cytokinin. Proc. Natl. Acad. Sci. USA 84:89-93.

Shoseyov, O., and Doi, R. H. 1990. Essential 170 kDa subunit for degradation of crystalline cellulose by Clostridium cellulovorans cellulase. Proc. Natl. Acad. Sci. USA 87:2192-2195.

Templeton, M. D., Rikkerink, E. H. A., and Beever, R. E. 1994. Small, cysteine-rich proteins and recognition in fungal-plant interactions. Mol. Plant-Microbe Interact. 7:320-325.

Umemoto, N., Kakitani, M., Iwamatsu, A., Yoshikawa, M., Yamaoka, N., and Ishida, I. 1997. The structure and function of a soybean $\beta$ glucan-elicitor-binding protein. Proc. Natl. Acad. Sci. USA 94:10291034.

Van den Ackerveken, G. F. J. M., van Kan, J. A. L., and De Wit, P. J. G. M. 1992. Molecular analysis of the avirulence gene $a v r 9$ of the fungal tomato pathogen Cladosporium fulvum fully supports the gene-forgene hypothesis. Plant J. 2:359-399.

Véronési, C., Fournier, J., Rickauer, M., Marolda, M., and EsquerréTugayé, M. T. 1995. Nucleotide sequence of an elicitor-induced tobacco lipoxygenase cDNA. Plant Physiol. 108:1342.

Wevelsiep, L., Kogel, K. H., and Knogge, W. 1991. Purification and characterization of peptides from Rhynchosporium secalis inducing necrosis in barley. Physiol. Mol. Plant Pathol. 39:471-482.

Wyatt, S. E., and Carpita, N. C. 1993. The plant cytoskeleton-cell-wall continuum. Trends Biol. Sci. 3:413-417.

Yu, L. M. 1995. Elicitins from Phytophthora and basic resistance in tobacco. Proc. Natl. Acad. Sci. USA 92:4088-4094. 